\title{
Control of oxidative stress and metabolic homeostasis by the suppression of postprandial hyperglycemia
}

\author{
Eiji Takeda, Hidekazu Arai, Hironori Yamamoto, Hisami Okumura, and Yutaka Taketani \\ Department of Clinical Nutrition, Institute of Health Biosciences, and The University of Tokushima \\ Graduate School, Tokushima, Japan
}

\begin{abstract}
Repeated mental stress may lead to chronic alterations in cortisol and catecholamine concentrations and to insulin resistance. Furthermore, chronically elevated cortisol concentrations may favour the development of abdominal obesity and of the metabolic syndrome. Oxidative stress impairs glucose uptake in muscle and fat and correlates with BMI. Obese subjects with type 2 diabetes, especially soon after the onset of diabetes, usually exhibit postprandial hyperglycemia with delayed hyperinsulinemia. It is recognized that insulin resistance causes postprandial hyperglycemia ; however, it is also possible that impairment of early insulin secretion in response to an oral glucose load is the reason why postprandial hyperglycemia occurs. Since even modest increases in postprandial glucose values can be a risk factor for cardiovascular disease. Therefore, the effects of palatinose based functional food which reduces postprandial hyperglycemia and hyperinsulinemia were investigated in rats. This novel food definitely reduced visceral fat accumulation and improved insulin sensitivity. Therefore, it is suggested that functional food which suppresses postprandial glucose level is beneficial for both stress and metabolic controls. J. Med. Invest. 52 Suppl. : 259-265, November, 2005
\end{abstract}

Keywords : stress, appetite, inflammation, functional food, metabolic control

\section{STRESS AND APPETITE}

Eating is thought to be suppressed during stress due to anorectic effects of corticotrophin releasing hormone, and increased during recovery from stress due to appetite stimulating effects of residual cortisol (1). Cortisol clearly plays an important role in energy regulation, increasing available energy through gluconeogenesis and lipolysis. Glucocorticoids lead to hyperphagia and weight gain, and are necessary for the expression of their obesity (2).

Received for publication September 9, 2005 ; accepted September 16, 2005.

Address correspondence and reprint requests to Eiji Takeda, M.D., Ph. D., Department of Clinical Nutrition, Institute of Health Biosciences, The University of Tokushima Graduate School, Kuramoto-cho, Tokushima 770-8503, Japan and Fax : +81-88-6337094.
Several studies have shown that people under chronic stress tend to gain weight over time, which may be due to both stress- related endocrine changes, as well as coping behaviors (3). It was hypothesized that high cortisol reactivity in response to stress may lead to eating after stress, given the relations between cortisol with both psychological stress and mechanisms affecting hunger. High cortisol reactors consumed more energy on the stress day compared to low reactors, high reactors ate significantly more sweet food across days. Increases in negative mood in response to the stressors were also significantly related to greater food consumption. Thus, psychophysiological response to stress influences subsequent eating behavior. In the current study of college undergraduate women (4), dieting was related to eating less during a control day, whereas cortisol reactivity predicted eating 
more on a stress day. Multiple comparisons of food type consumed by reactivity group revealed further differences of the sweet food consumed after stress, the high reactors consumed significantly more high fat food.

\section{STRESS AND IMPAIRED CARBOHYDRATE AND LIPID METABOLISM}

Responses to mental stress involves activation of the sympathetic nervous system and secretion of epinephrine from the adrenal medulla and activation of the hypothalamo-pituitary adrenal axis, the latter resulting in the secretion of glucocorticoids from the adrenal cortex. The combined effects of these neuroendocrine alterations are the mobilization of lipids from the adipose tissue and of glucose from hepatic glycogen to ensure ample energy availability together with the development of an acute state of insulin resistance, which diverts glucose away from skeletal muscle to ensure glucose supply to the brain.

Mental stress significantly enhances plasma catecholamine and cortisol concentrations, but does not acutely impair insulin sensitivity (5). Repeated mental stress may lead to chronic alterations in cortisol and catecholamine concentrations and to insulin resistance. Furthermore, chronically elevated cortisol concentrations may favour the development of abdominal obesity and of the metabolic syndrome $(6,7)$ (Fig. 1). Repeated mental stress particularly in obese patients can contribute to increased blood pressure and to increased plasma glucose concentrations.

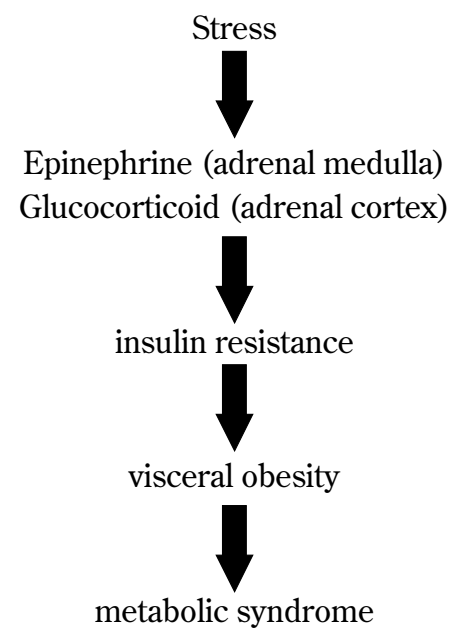

Fig. 1 Mental stress leads to insulin resistance and to the metabolic syndrome.

\section{STRESS AND INFLAMMATION}

It has been recognized that low-grade, chronic inflammation is present in individuals at risk of developing atherosclerotic disorders (8). Obese insulin-resistant individuals show increased tumor necrosis fantor- $\alpha$ (TNF- $\alpha$ ) and interleukin (IL) concentrations in plasma, adipose tissue and skeletal muscle (9-11). TNF- $\alpha$ and other pro-inflammatory cytokines acutely reduced insulin sensitivity (1214). Dietary factors can modulate the expression of these cytokines in insulin-sensitive tissue. In particular, a high-fat diet appears to reduce insulin sensitivity by activating inflammatory responses in adipose tissue through the stimulation of the inhibitor of nuclear factor kappa B (NF-kB) (15).

Several studies demonstrated that psychological stress stimulates the production of pro-inflammatory cytokines. In elderly individuals, the chronic stress of looking after a dementing spouse led to increased plasma IL-6 concentrations. Raised plasma concentrations of pro-inflammatory cytokines were recorded in individuals expecting an academic examination (16). Both chronic psychological stress and acute mental stress have been demonstrated to increase pro-inflammatory cytokines $(17,18)$. The pathways responsible for the stimulation of cytokine release involve activation of the sympathetic nervous system (19). In humans, mental stress acutely activated NF-kB, a nuclear factor acting upstream of the inflammatory cascade, in peripheral blood mononuclear cells (20).

\section{OXIDATIVE STRESS AND INSULIN RE- SISTANCE}

Obese subjects with type 2 diabetes, especially soon after the onset of diabetes, usually exhibit postprandial hyperglycemia with delayed hyperinsulinemia. It is recognized that insulin resistance causes postprandial hyperglycemia $(21,22)$; however, it is also possible that impairment of early insulin secretion in response to an oral glucose load is the reason why postprandial hyperglycemia occurs (23). Since even modest increases in postprandial glucose values can be a risk factor for cardiovascular disease (24), patients with diabetes would probably benefit from early and effective mealtime treatment. The mealinduced activation of homeostasis in patients with type 2 diabetes can be reduced by decreasing postprandial hyperglycemia (25). 
Oxidative stress is widely invoked as a pathogenic mechanism for atherosclerosis. Among the sequelae of hyperglycemia, oxidative stress has been suggested as a potential mechanism for accelerated atherosclerosis (26-28). Hyperglycemia can increase oxidative stress through several pathways. A major mechanism appears to be the hyperglycemia-induced intracellular reactive oxygen species (ROS), produced by the proton electromechanical gradient generated by the mitochondria electron transport chain and resulting in increased production of superoxide (26). Oxidative stress impairs glucose uptake in muscle and fat (29-30) and decreases insulin secretion from pancreatic $\beta$ cells (31).

It has been demonstrated in nondiabetic human subjects that fat accumulation closely correlated with the markers of systemic oxidative stress and that plasma adiponectin levels correlated inversely with systemic oxidative stress (32). Those are in good agreement with data suggesting that systemic oxidative stress correlates with BMI $(33,34)$. It is suggested that increased ROS secretion into peripheral blood from accumulated fat in obesity is also involved in induction of insulin resistance in skeletal muscle and adipose tissue, impaired insulin secretion by $\beta$ cells.

Therefore, strategies to reduce postprandial hyperglycemia and hyperinsulinemia represent an important approach to improving glycemic control in patients with type 2 diabetes mellitus and may even prevent the deterioration of glucose metabolism in impaired glucose tolerance and the subsequent progression to diabetes.

\section{PREPARATION OF PALATINOSE BASED FUNCTIONAL FOOD}

Palatinose (isomaltulose), which is present in honey, has shown promise as a noncariogenic caloric sweetener $(35,36)$. A previous study clearly demonstrated that the increase in plasma glucose (PG) and insulin (IRI) after palatinose ingestion was significantly smaller than that after sucrose (37). Furthermore, palatinose has been shown to be an insulin-sparing caloric sweeteer with a lower glycemic index than sucrose in type 2 diabetic patients and streptozotocin-diabetic animals $(38,39)$. The difference may be due to a difference in digestibility because palatinose is digested to glucose and fructose by the intestinal isomaltase, and the hydrolysis of palatinose by a homogenate of human intestinal mucosa was one-fourth that of sucrose (40). However, palatinose was completely cleaved and absorbed (41).

The novel enteral liquid formula designated as Inslow was prepared by the replacement of dextrin in the standard balanced formula (SBF) with $55.7 \%$ palatinose among carbohydrate (Table 1) (41). Inslow contains palatinose, branched dextrin, xylitol, and other carbohydrates containing dietary fiber and mixed carbohydrates from raw material as the principal carbohydrates, and the percentages of protein, fat, and carbohydrate in the formula are $20 \%, 29.7 \%$, and $50.3 \%$, respectively. The commercially available SBF that was used for comparison contains dextrin and sucrose as the principal carbohydrates, and the percentages of protein, fat, and carbohydrate are $16 \%, 25 \%$, and $59 \%$, re-

Table 1 Composition of Inslow and standard balanced formula (SBF)

\begin{tabular}{clcc}
\hline & Inslow & $\begin{array}{c}\text { Standard balanced } \\
\text { formula(SBF) }\end{array}$ \\
\hline Energy & $1 \mathrm{kcal} / \mathrm{ml}$ & $1 \mathrm{kcal} / \mathrm{ml}$ \\
$\bigcirc$ Protein & $20.0 \%$ & $6.0 \%$ \\
$\bigcirc$ & Fat & $29.7 \%$ & $25.0 \%$ \\
SFA & $9.5 \%$ & $9.0 \%$ \\
MUFA & $68.5 \%$ & $45.0 \%$ \\
PUFA & $16.8 \%$ & $40.0 \%$ \\
Carbohydrate & $50.3 \%$ & $59.0 \%$ \\
Maltodextrin & $22.8 \%$ & Sucrose & $2.8 \%$ \\
Xylitol & $8.9 \%$ & Dextrin & $97.2 \%$ \\
Paratinose & $68.3 \%$ & & \\
\hline
\end{tabular}

Abbreviations : SFA, saturated fatty acid ; MUFA, monounsaturated fatty acid ; PUFA, polyunsaturated fatty acid 
spectively. Spray-dried powder versions of Inslow and SBF were prepared for use in the long term study.

\section{CONTROL OF METABOLIC HOMEOSTASIS BY THE SUPPRESSION OF POSTPRAN- DIAL HYPERGLYCEMIA}

The effect of Inslow on carbohydrate and lipid metabolism in Sprague-Dawley rats were compared with those of SBF (42). After a bolus intragastric injection of each formula equivalent to 0.9 $\mathrm{g} / \mathrm{kg}$ carbohydrate, the peak levels of PG and IRI in the femoral vein of the Inslow group were sig-

(A)

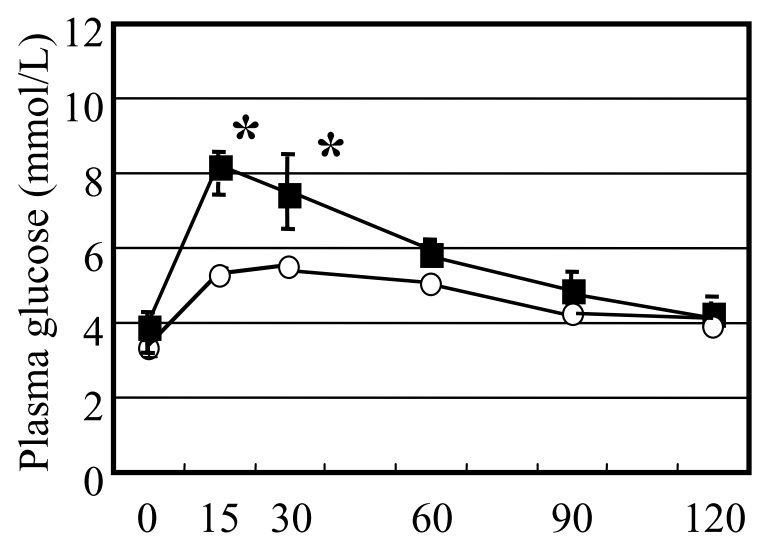

nificantly smaller than those of SBF group (Fig. 2 ). The values of total incremental area (area under the curve : AUC) of PG and IRI from the basal level for $120 \mathrm{~min}$ after INSLOW ingestion were significantly smaller than that after SBF ingestion (Fig. 3).

From 20 to 27 weeks of age, daily food intake and body weight did not differ significantly among the Inslow and SBF groups; however, body weight gain in the Inslow group was lower than in SBF group. After ingestion of Inslow or SBF for two months, fasting PG levels were not different among the two groups, but the IRI level in the Inslow group was significantly lower than that in the SBF group. The TG level markedly decreased by $34 \%$

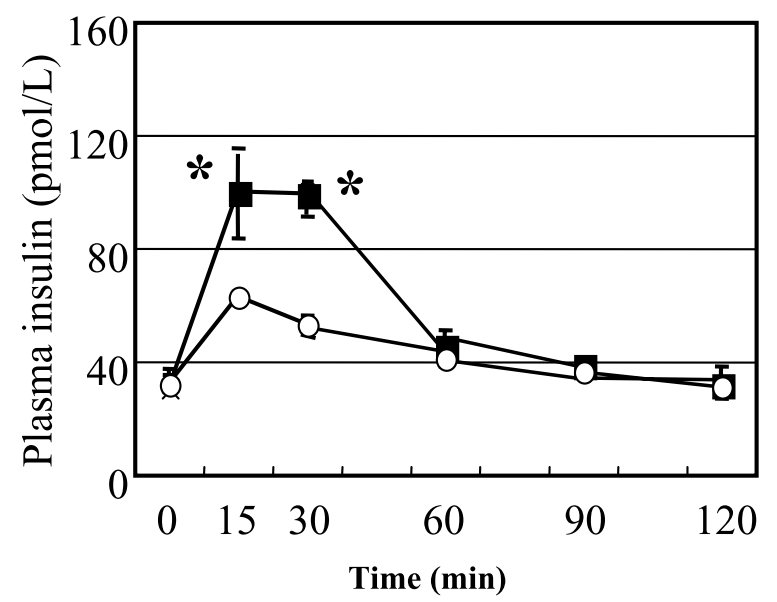

Fig. 2 Changes in plasma glucose (PG) (A) and plasma insulin (IRI) (B) in the femoral vein after oral administration of Inslow (white circles) and SBF (black squares). Values are means \pm SE for $n=10 .^{*}: p<0.001$ (vs. Inslow)

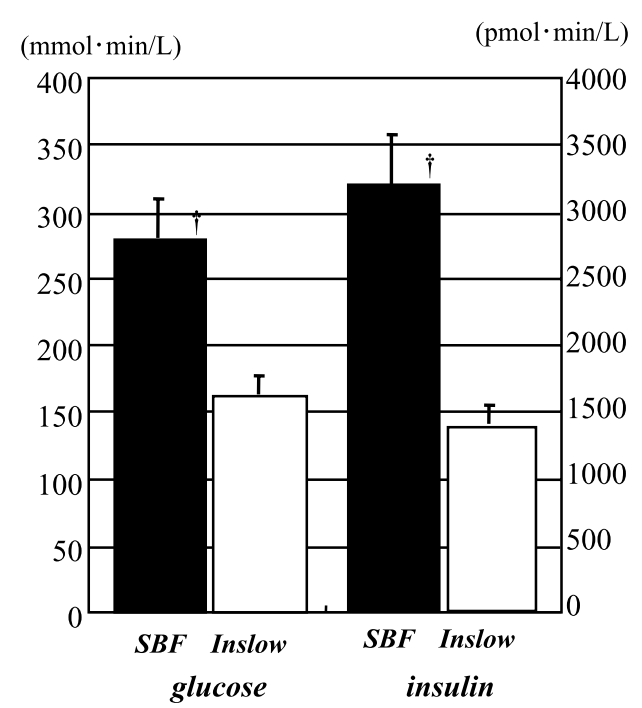

Fig. 3 Area under the curve (AUC) after 120 min of PG and IRI in the femoral vein during oral administration of Inslow (white bar) or SBF (black bar). Values are means \pm SE for $\mathrm{n}=10 . \dagger: \mathrm{p}<0.01$ (vs. Inslow) in the Inslow group and increased by $23 \%$ in the SBF group. The TG level of the Inslow group was significantly lower than that of the SBF group. The concentrations of serum free fatty acid (FFA) and total cholesterol did not differ among the two groups.

The weights of epididymal, mesenteric, and retroperitoneal adipose tissues were significantly lower in the Inslow group than in the SBF group. The weights of liver and pancreas in the Inslow group were higher than in the SBF group. The concentration of TG in the liver in the Inslow group was significantly lower than that in the SBF group. Insulin sensitivity in the Inslow and SBF groups was evaluated by the hyperinsulinemic euglycemic clamp test with oral glucose load. The glucose infusion rate (GIR), which reflected the insulin sensitivity in peripheral tissues, of the Inslow group was significantly higher than that of the SBF group 
(Fig. 4). The rate of hepatic glucose uptake (HGU), which might reflect insulin sensitivity in the liver, was significantly higher in the Inslow group than in the SBF group (Fig. 4).
A

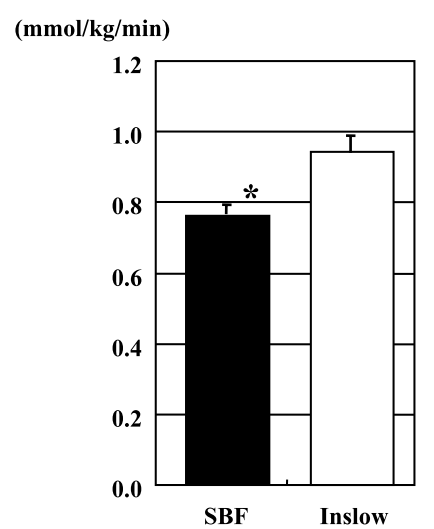

B

(\%)

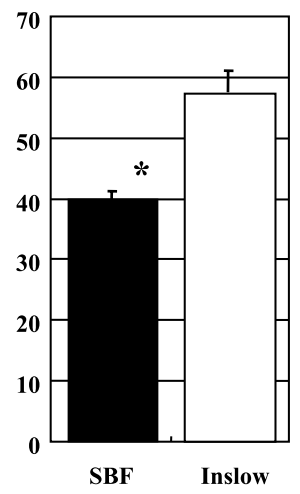

Fig. 4 Glucose infusion rate (A) and hepatic glucose uptake (B) during hyperinsulinemic euglycemic clamp with oral glucose load in Inslow (white bar) and SBF (black bar) groups. Values are means $\pm \mathrm{SE}$ for $\mathrm{n}=10$. $^{*}: \mathrm{p}<0.05$ (vs. Inslow)

\section{CONCLUSION}

Postprandial glucose and insulin levels affects body weight and body fat even though the intake was same amount of energy. The effects of Inslow could be due to the suppression of the excess calories exposed in adipocytes which was controlled by insulin. In addition, increased ROS production observed by postprandial hyperglycemia leads to increased oxidative stress in blood and other organs.

Both metabolic and epidemiologic evidence suggest that replacing high-glycemic-index forms of carbohydrate with low-glycemic-index carbohydrates could reduce the risk of type 2 diabetes (43). Differences in the pattern of postprandial glucose response offer a potential explanation for the conflicting results on insulin sensitivity, with possibility that increases in insulin exposure may affect insulin sensitivity through down-regulation of insulin action (44). Therefore, it is suggested that Inslow which suppresses postprandial glucose level is beneficial for both stress and metabolic controls.

\section{ACKNOWLEDGEMENTS}

This work was supported in part, by Grants-inAid for Scientific Research from the Ministry of
Education, Culture, Sports, Science, and Technology in Japan and the 21 st Cenrury COE Program, Human Nutritional Science and Stress Control, Tokushima, Japan.

\section{REFERENCES}

1. Sapolsky R: Why Zebras don't get Ulcers : An Updated Guide to Stress, Stress-related Diseases, and Coping. Freeman and Co, New York, 1998, pp.76-79

2. Bray $\mathrm{G}$ : Autonomic and endocrine factors in the regulation of food intake. Brain Research Bulletin 14 : 505-510, 1985

3. Greeno C, Wing R, Matthews K, Vitaliano P : Stress predicts overeating and weight gain outside of the laboratory : data from multiple studies. Annals of Behavioral Medicine 20:S032, 1998

4. Epel E, Lapidus R, McEwen B, Brownell K: Stress may add bite to appetite in women : a laboratory study of stress-induced cortisol and eating behavior. Psychoneuroendocrinol 26 : 37-49, 2001

5. Seematter G, Guenat E, Schneiter P, Cayeux C, Jequier E, Tappy L: Effects of mental stress on insulin-mediated glucose metabolism and energy expenditure in lean and obese women. American Journal of Physiology 279 : E799-E 805, 2000

6. Bjorntorp $\mathrm{P}$ : The regulation of adipose tissue distribution in humans. International Journal of Obesity and Related Metabolic Disorders 20 : 291-302, 1996

7. Masuzaki H, Paterson J, Shinyama H, Morton NM, Mullins JJ, Seckl JR, Flier JS : A transgenic model of visceral obesity and the metabolic syndrome. Science $294: 2166-2170,2001$

8. Casscells W, Naghavi M, Willerson JT: Vulnerable atherosclerotic plaque : a multifocal disease. Circulation 107 : 2076-2077, 2003

9. Hotamisligil GS, Arner P, Caro JF, Atkinson RL, Spiegelman BM : Increased adipose tissue expression of tumor necrosis factor-a in human obesity and insulin resistance. The Journal of Clinical Investigation 95 : 2409-2415, 1995

10. Hotamisligil GS, Shargill NS, Spiegelman BM : Adipose expression of tumor necrosis factoralpha ; direct role in obesity-linked insulin resistance. Science 259 : 87-91, 1993

11. Saghizadeh M, Ong JM, Garvey WT: The ex- 
pression of TNF-a by human muscle : relationship to insulin resistance. The Journal of Clinical Investigation 97 : 1111-1116, 1996

12. Miles PD, Romeo OM, Higo K, Cohen A, Rafaat K, Olefsky JM:TNF-alpha-induced insulin resistance in vivo and its prevention by troglitazone. Diabetes 46 : 1678-1683, 1997

13. Ruan H, Miles PD, Ladd CM, Ross K, Golub TR, Olefsky JM, Lodish HF : Profiling gene transcription in vivo reveals adipose tissue as an immediate target of tumor necrosis factoralpha : implications for insulin resistance. Diabetes $51: 3176-3188,2002$

14. van Hall G, Steensberg A, Sacchetti M, Fischer C, Keller C, Schjerling P, Hiscock N, Moller K, Saltin B, Febbraio MA, Pedersen BK: Interleukin-6 stimulates lipolysis and fat oxidation in humans. The Journal of Clinical Endocrinology \& Metabolism 88 : 3005-3010, 2003

15. Yuan M, Konstantopoulos N, Lee J, Hansen L, Li ZW, Karin M, Shoelson SE : Reversal of obesity and diet-induced insulin resistance with salicylates or targeted disruption of Ikkb. Science 293 : 1673-1677, 2001

16. Maes M, Van der Planken M, Van Gastel A, Bruyland K, Van Hunsel F, Neels H, Hendriks D, Wauters A, Demedts P, Janca A, Scharpe $\mathrm{S}$ : Influence of academic examination stress on hematological measurements in subjectively healthy volunteers. Psychiatry Research 80 : 201-212, 1998

17. Steptoe A, Willemsen G, Owen N, Flower L, Mohamed-Ali V: Acute mental stress elicits delayed increases in circulating inflammatory cytokine levels. Clinical Science 101:185-192, 2001

18. Steptoe A, Owen N, Kunz-Ebrecht S, MohamedAli V : Inflammatory cytokines, socioeconomic status, and acute stress responsivity. Brain Behavior and Immunity $16: 774-784,2002$

19. Tracey $\mathrm{KJ}$ : The inflammatory reflex. Nature 420 : 853-859, 2002

20. Bierhaus A, Wolf J, Andrassy M, Rohleder N, Humpert PM, Petrov D, Ferstl R, von Eynatten M, Wendt T, Rudofsky G, Joswig M, Mor$\cos$ M, Schwaninger M, McEwen B, Kirschbaum $\mathrm{C}$, Nawroth PP : A mechanism converting psychosocial stress into mononuclear cell activation. Proceedings of the National Academy of Sciences of the United States of America $100: 1920-1925,2003$

21. Lillioja S, Mott DM, Howard BV, Bennett PH, Yki-Jarvinen H, Freymond D, Nyomba BL,
Zurlo F, Swinburn B, Bogardus C : Impaired glucose tolerance as a disorder of insulin action : Longitudinal and cross-sectional studies in Pima Indians. New England Journal of Medicine 318 : 1217-1225, 1988

22. Reaven G, Miller R: Study of the relationship between glucose and insulin responses to an oral glucose load in man. Diabetes 17:560-569, 1968

23. Bruce DG, Chisholm DJ, Storlien LH, Kraegen EW : Physiological importance of deficiency in early prandial insulin secretion in non-insulindependent diabetes. Diabetes 37 : 736-744, 1988

24. United Kingdom Prospective Diabetes Study (UKPDS). 13 : relative efficacy of randomly allocated diet, sulphonylurea, insulin, or metformin in patients with newly diagnosed noninsulin-dependent diabetes followed for three years. British Medical Journal 310:83-88, 1995

25. DiMarchi RD, Chance RE, Long HB, Shields JE, Slieker LJ : Preparation of an insulin with improved pharmacokinetics relative to human insulin through consideration of structural homology with insulin-like growth factor 1 . Hormone Research 41 (Suppl 2) : 93-96, 1994

26. Nishikawa T, Edelstein D, Du XI, Yamagishi S, Matsumura T, Kaneda Y, Yorek MA, Beebe D, Oates PJ, Hammes HP, Giardino I, Brownlee $\mathrm{M}$ : Normalizing mitochondria) superoxide production blocks three pathways of hyperglycaemic damage. Nature $404: 787-790,2000$

27. Baynes JW, Thorpe SR : Role of oxidative stress in diabetic complications : a new perspective on an old paradigm. Diabetes $48: 1-9,1999$

28. Baynes JW : Role of oxidative stress in development of complications in diabetes. Diabetes 40 : 405-412, 1991

29. Maddux BA, See W, Lawrence JC Jr, Goldfine AL, Goldfine ID, Evans JL: Protection against oxidative stress-induced insulin resistance in rat L6 muscle cells by micromolar concentrations of $\alpha$-lipoic acid. Diabetes 50 : 404-410, 2001

30. Rudich A, Tirosh A, Potashnik R, Hemi R, Kanety $\mathrm{H}$, Bashan $\mathrm{N}$ : Prolonged oxidative stress impairs insulin-induced GLLJT 4 translocation in 3T3-L1 adipocytes. Diabetes 47 : 1562-1569, 1998

31. Matsuoka T, Kajimoto Y, Watada H, Kaneto H, Kishimoto M, Umayahara Y, Fujitani Y, Kamada T, Kawamori R, Yamasaki Y : Glycationdependent, reactive oxygen species-mediated suppression of the insulin gene promoter activity in HIT cells. The Journal of Clinical In- 
vestigation $99: 144-150,1997$

32. Furukawa S, Fujita T, Shimabukuro M, Iwaki M, Yamada Y, Nakajima Y, Nakayama O, Makishima M, Matsuda M, Shimomura I: Increased oxidation stress in obesity and its impact on metabolic syndrome. The Journal of Clinical Investigation 114 : 1752-1764, 2004

33. Keaney JF Jr, Larson MG, Vasan RS, Wilson PW, Lipinska I, Corey D, Massaro JM, Sutherland P, Vita JA, Benjamin EJ : Obesity and systemic oxidative stress : clinical correlates of oxidative stress in the Framingham Study. Arteriosclerosis Thrombosis and Vascular Biology 23 : 434-439, 2003

34. Olusi SO : Obesity is an independent risk factor for plasma lipid peroxidation and depletion of erythroryte cytoprotective enzymes in humans. International Journal of Obesity and Related Metabolic Disorders 26 : 1159-1164, 2002

35. Siddiqui IR, Furgala B : Isolation and characterization of oligosaccharides from honey. Part 1. Disaccharides. J Api Res 6 : 39-145, 1967

36. Lingstrom P, Lundgren F, Birkhed D, Takazoe I, Frostell G: Effects of frequent mouthrinses with palatinose and xylitol on dental plaque. European Journal of Oral Sciences 105 : 162169, 1997

37. Kawai K, Okuda Y, Yamashita K : Changes in blood glucose and insulin after an oral palatinose adlninistration in normal subjects. Endocrinologia Japonica 32 : 933-936, 1985

38. Kawai K, Yoshikawa H, Murayama Y, Okuda $\mathrm{Y}$, Yamashita K : Usefulness of palatinose as a caloric sweetener for diabetic patients. Hormone and Metabolic Research $21: 338-340,1989$
39. Okuda Y, Kawai K, Chiba Y, Koide Y, Yamashita K: Effects of parenteral palatinose on glucose metabolism in normal and streptozotocin diabetic rats. Hormone and Metabolic Research 18: 361-364, 1986

40. Dahlquist A, Auricchio S, Semenza G, Prader A: Human intestinal disaccharidases and hereditary disaccharide intolerance : The hydrolysis of sucrose, isomaltose, palatinose (isomaltulose), and 1,6- $\alpha$-oligosaccharid(isomaltooligosaccharide) preparation. The Journal of Clinical Investigation $42: 556-562,1963$

41. Lina BAR, Jonker D, Kozianowski G : Isomaltulose (palatinose) : a review of biological and toxicological studies. Food and Chemical Toxicology 40 : 1375-1381, 2002

42. Arai H, Mizuno A, Matsuo K, Fukaya M, Sasaki H, Arima H, Matsuura M, Taketani Y, Doi T, Takeda E : Effect of a Novel PalatinoseBased Liquid Balanced Formula (MHN-01) on Glucose and Lipid Metabolism in Male Sprague-Dawley Rats After Short-and LongTerm Ingestion. Metabolism 53(8) : 977-983, 2004

43. Peters AL, Davidson MB : Effects of various enteral feeding products on postprandial blood glucose response in patients with type 1 diabetes. The Japanese Journal of Parenteral and Enteral Nutrition 16 : 69-74, 1992

44. Craig LD, Nicholson S, Silverstone FA, Kennedy $\mathrm{RD}$ : Use of a reduced-carbohydrate, modifiedfat enteral formula for improving metabolic control and clinical outcomes in long-term care residents with type 2 diabetes: Results of a pilot trial. Nutrition $14: 529-534,1998$ 